\title{
Comparative analysis of the venom proteome of four important Malaysian snake species
}

\author{
Jaya Vejayan ${ }^{1 *}$, Too Lay Khoon² and Halijah Ibrahim²
}

\begin{abstract}
Background: Naja kaouthia, Ophiophagus hannah, Bungarus fasciatus and Calloselasma rhodostoma are four venomous snakes indigenous to Malaysia. In the present study, their proteomic profile by two-dimensional gel electrophoresis (2-DE) have been separated and compared.

Results: The 2-DE of venoms of the four species snake demonstrated complexity and obvious interspecies differences in proteome profiles. A total of 63 proteins were identified in the four species: C. rhodostoma $-26, N$. kaouthia - 16, O. hannah - 15 and B. fasciatus - 6 .

Conclusions: Despite the identifications of major proteins in the four snake species, a large number of protein spots from the 2-DE were unidentified even though the spots displayed high-quality MALDI-TOF-MS spectra. Those identified included phospholipase $A_{2}$ proteins in all four venoms, long neurotoxins in both cobra species and the $C$. rhodostoma venom found with the most varied types of peptidases, i.e. metalloproteinase kistomin, halystase and L-amino acid oxidase.
\end{abstract}

Keywords: Mass spectrometry, Snake venoms, Proteomics, Two-dimensional gel electrophoresis

\section{Background}

In Malaysia, more specifically Peninsular Malaysia, a very rich snake fauna is present, consisting of approximately 141 known species of land and sea snakes. Of these, only 16 species of land snakes and all 21 sea snake species are venomous [1]. This study focused on four of these venomous species, namely Naja kaouthia, Ophiophagus hannah, Bungarus fasciatus and Calloselasma rhodostoma. The first three are of the Elapidae family while C. rhodostoma belongs to the Viperidae family. The venoms of $N$. kaouthia (monocled cobra, 1.5-2.0 meters long), O. hannah (king cobra, 3 to 4 meters long) and B. fasciatus (banded kraits, 1.6 meters long) are comprised mainly of neurotoxins [2,3]. Other potent basic polypeptides - such as cardiotoxin, cytotoxin and cobramines - are also found abundantly in the venoms of elapids. The short-tempered, quick-to-attack cobra is one of the most frightening; while kraits, though much more subdued, are also highly feared for their toxic, frequently death-causing bites. The venom of C. rhodostoma (Malayan pit viper, 0.6-1 meters long,

\footnotetext{
* Correspondence: jayavejayan@yahoo.com

${ }^{1}$ Faculty of Industrial Sciences and Technology, University Malaysia Pahang, Lebuhraya Tun Razak, Kuantan, Pahang Darul Makmur 26300, Malaysia Full list of author information is available at the end of the article
}

previously known as Agkistrodon rhodostoma and Ancistrodon rhodostoma), is rich in peptidases that exhibit hemorrhagic activities and is capable of affecting blood coagulation, leading to a hemotoxic effect [4].

Since the early biochemical characterization of venoms, scientists have been unravelling the biological and pathological significance of their proteins and peptides. The advances in mass spectrometry (MS) for protein identification have revolutionized snake venom proteomics, shedding light into the global complexity of venom proteomes and, subsequently, their pathological activities. Using a multitude of proteomic approaches, venom proteomes have been analyzed in 55 snake genera [3]. The application of proteomics, including the use of two-dimensional gel electrophoresis (2-DE) and MS in studying venoms, has attracted considerable attention from researchers. The effective use of the 2-DE technique, coupled with MS, was first demonstrated in a study conducted by Fox and colleagues [5] in their comparative analysis of the venoms of Dispholidus typus, Crotalus atrox and Bothrops jararaca. The correlation between genetic, ecological and phylogeny factors with intraspecific variations in the composition of the Trimeresurus stejnegeri venom was investigated by Creer and 
colleagues [6] by employing matrix-assisted laser desorption ionization-time-of-flight (MALDI-TOF)/MS and isoelectric-focusing (IEF) technologies. To further assess the extreme complexity of natural venoms, Li et al. [2] assessed the global venom proteomics profiles of Naja naja atra and Agkistrodon halys by a combination of four different approaches. Nawarak et al. [7], on the other hand, used 2-DE and MALDI-TOF MS to identify moderate- to high-molecular-mass glycoproteins in $N$. kaouthia venom, which had been previously fractionated by binding with concanavalin A. These approaches have also been utilized for the characterization of novel proteins that are yet to be inserted into protein databases. For instance, MALDI-TOF MS has been employed to determine the molecular mass of purified proteins while 2-DE has been used to ascertain both the molecular weights as well as pI values of isolated proteins [8-10].

Numerous additional investigations into venom proteomes and subproteomes, using a wide array of proteomic strategies, have provided novel insights into venom contents, their biological activities and the evolutionary relationships among snakes [3]. Nevertheless, as experienced by $\mathrm{Li}$ et al. [2], only $50 \%$ of the spots were confirmed to be venom proteins although approximately $80 \%$ of the gel spots from 2-DE displayed high-quality MALDI-TOF MS spectra. Scarcity of venom sequence databases for the analysis of MS data has posed a challenge to all snake venom proteomic studies. Proteomics tools provide enormous versatility in diverse applications, ranging from unravelling the complexity of varies venoms to potentially identifying the minute differences between very closely related organisms [11]. The current study aims to further underline the importance and challenges of proteomics in the study of snake venom by profiling the venom of four snake species indigenous to Malaysia.

\section{Methods}

\section{Snake venoms}

All venoms used were from common venomous snakes in Malaysia, obtained from a local vendor, Bukit Bintang Enterprise Sdn Bhd. The venoms were freeze-dried and stored at $-20^{\circ} \mathrm{C}$.

\section{Protein content determination}

The protein content in the four venoms was estimated using the dye-binding technique of Bradford [12] with bovine serum albumin (BSA) at $2.0 \mathrm{mg} / \mathrm{mL}$ concentration, purchased from Thermo Scientific.

\section{Two-dimensional Gel electrophoresis (2-DE)}

Eighteen-centimeter IPG strips (GE Healthcare, Sweden) with a linear $\mathrm{pH}$ range of 3 to 10 were rehydrated overnight with $340 \mu \mathrm{L}$ of rehydration solution. After rehydration, the IPG strips were introduced with the venomous proteins $(100 \mu \mathrm{g}$ for silver staining and $300 \mu \mathrm{g}$ for Coomassie blue staining) via a sample-loading cup. Prior to this the venomous proteins had been dissolved in $100 \mu \mathrm{L}$ of rehydration solution containing $8 \mathrm{M}$ urea, $2 \%$ (w/v) CHAPS, $20 \mathrm{mM}$ DTT (dithiothreitol), 0.5\% (v/v) IPG buffer, 0.002\% (w/v) Bromophenol blue. Electrofocusing was carried out at $30 \mathrm{kVh}$ using IPGphor (GE Healthcare) at $20^{\circ} \mathrm{C}$ according to the manufacturer's instruction. Before the second dimensional electrophoresis, the IPG strips were equilibrated by two equilibration steps: reduction buffer with $50 \mathrm{mM}$ Tris/HCL, pH 8.8, $6 \mathrm{M}$ urea, 30\% (v/v) glycerol, 2\% (w/v) SDS, a trace of Bromophenol blue and $1 \%(\mathrm{w} / \mathrm{v})$ DTT on a rocking table for ten minutes; alkylation buffer with $50 \mathrm{mM}$ Tris/HCL, pH 8.8, $6 \mathrm{M}$ urea, $30 \%(\mathrm{v} / \mathrm{v})$ glycerol, $2 \%(\mathrm{w} / \mathrm{v})$ SDS, a trace of Bromophenol blue and $2.5 \%(\mathrm{w} / \mathrm{v})$ iodoacetamide for an additional ten minutes. The equilibrated strips were loaded and run on $15 \%$ polyacrylamide Laemmli gels $(26 \mathrm{~cm} \times 20 \mathrm{~cm})$ using the Ettan Dalt II system (GE Healthcare) with a programmable power control, initially $0.5 \mathrm{~W}$ per gel for 40 minutes, followed by $15 \mathrm{~W}$ per gel till the dye front reached the bottom of the gel. The separated gel proteins were visualized by Coomassie brilliant blue.

\section{MALDI-TOF MS}

The Coomassie-stained gels were scanned using the Image Scanner (Amersham Biosciences Limited, Sweden) and the spots were detected, edited and annotated with ImageMaster 2D Platinum ${ }^{\circledR}$ software (Amersham Biosciences Limited, Sweden). The stained spots were selected, excised and dehydrated with $50 \mu \mathrm{L}$ of acetonitrile for 15 minutes. To rehydrate, the supernatant was then replaced with $25 \mu \mathrm{L}$ of $25 \mathrm{mM} \mathrm{NH}_{4} \mathrm{HCO}_{3}$ for ten minutes. These steps of rehydration followed by dehydration were repeated to give a total of three washes. Finally, the spots were dried for five minutes using a centrifugal evaporator $\left(\operatorname{SpeedVac}^{\circledR}\right.$, Thermo Scientific, USA).

\section{In-Gel tryptic digestion}

The dried spots were then re-suspended in $10 \mu \mathrm{L}$ of $10 \mathrm{ng} / \mu \mathrm{L}$ trypsin in $25 \mathrm{mM} \mathrm{NH} \mathrm{NCO}_{3}$ and incubated for complete digestion at $37^{\circ} \mathrm{C}$ overnight. On completion, the gel was once again dehydrated with the addition of acetonitrile. Finally, the gel piece was removed and the supernatant was dried down in the SpeedVac ${ }^{\circledR}$ for 20 minutes.

\section{Sample preparation for MS}

An equal amount of tryptic-digested samples was mixed together with a matrix solution consisting of $\alpha$-cyano-4hydroxy cinnamic acid in acetonitrile acidified with trifluroacetic acid $(1 \mathrm{mg} / \mathrm{mL})$. Thereafter, $0.4 \mu \mathrm{L}$ of this mixture was spotted on the slide and air-dried. 


\section{Mass spectrometry}

MALDI-TOF mass spectra of peptide mixture were obtained on an Ettan MALDI-TOF-Pro mass spectrometer (Amersham Biosciences AB, Sweden) by a delayed ion source with nitrogen laser of $337 \mathrm{~nm}$. The acceleration voltage was set to $20 \mathrm{kV}$ with positive ion reflectron mode. The low mass rejection was activated. The instrument was calibrated externally with peptide samples of adrenocorticotropic hormone and angiotensin III that gave respective spectrum peaks at 897.531 and 2465.199.

\section{Database searching}

Proteins were identified via monoisotopic masses (as shown in the table found in Additional file 1) with the aid of the Internet search program MASCOT (http:// www.matrixscience.com) as well as ExPASy (http://www. expasy.org). For the MASCOT search, the search parameters were: NCBInr database, SwissProt and/or MSDB; species: Chordata vertebrates and relatives; missed cleavages: 1; enzyme: trypsin, tolerance: $1.0 \mathrm{Da}$ and charge state: $\mathrm{MH}+$. The parameters for the ExPASy search were: Swiss-Prot database; species: other vertebrata; missed cleavages: 1; enzyme: trypsin, ion mode: $\mathrm{MH}^{+}$.

\section{Ethics statement}

This study required no approval by any animal ethics committee as decided by the Animal Ethics Committee of University Malaya based on reasoning that the study dealt with venom milked from snakes of the wild rather than experimenting on them in the laboratory. All precautions were taken to ensure no harm were inflicted on the snakes by an expert snake handler.

\section{Results}

Comparative analysis of 2-DE on various snake venoms In the first-dimension isoelectric focusing, $18 \mathrm{~cm}$ IPG ( $\mathrm{pH} 3-10)$ strips were used with the cup-loading technique, which was found to produce better results than sample application by in-gel rehydration. It was also ideal for separating the more basic proteins of the snake venoms when the loading cup is applied at the anodic site. Subsequently, the proteins were separated in the second dimension by $15 \%$ SDS-PAGE. The 2-DE images of the four snake venoms demonstrated different degrees of complexity in polypeptide constituents in general. The visual inspection of 2-DE maps showed notable differences in proteome profiles among the venoms of $N$. kaouthia, O. hannah, B. fasciatus and C. rhodostoma (Figure 1). In particular, basic (high pI) and lowmolecular-mass protein spots were found to be highly prominent in the venoms of $N$. kaouthia and B. fasciatus. This is typical of venom of Elapidae origin, which is comprised mainly of neurotoxins. Nawarak et al. [13] had also demonstrated similar proteomic profiles in snake venoms from Elapidae families using multidimensional chromatographic approaches. Nevertheless, the proteomic profiles of $O$. hannah displayed certain degrees of disparity against those of elapids and showed similarities with those of $C$. rhodostoma, where the venom proteins were evenly dispersed across the $\mathrm{pI}$ and mass range.

\section{Peptide mass fingerprinting (PMF) identification of protein spots from four snake venoms}

Spots were selected and carefully identified from the 2-DE gel stained by Coomassie blue, tryptic-digested, extracted and analyzed in duplicates per spot with MALDI-TOF MS in reflectron mode. Identification by PMF on proteins isolated from 2-DE gels of the four venoms was performed by scanning the monoisotopic masses with two separate Internet search programs, MASCOT (http://www.matrixscience.com/cgi/search_form.pl? FORMVER=2\&SEARCH=PMF) and ExPASy (previously located URL: http://www.expasy.org/tools/aldente/). In PMF, the profile of the unknown protein was compared with theoretical peptide libraries generated from sequences in the different databases. Identified proteins were chosen from either MASCOT or ExPASy, which yielded more numerous hits and higher sequence coverage. The latter search program was taken out of the public domain and continued as a licensed database until recently discontinued altogether.

A total of $113,50,26$, and 115 spots were analyzed to obtain the venom protein compositions of N. kaouthia, $O$. hannah, B. fasciatus, and C. rhodostoma, respectively, but only the corresponding $34 \%, 86 \%, 54 \%$, and $40 \%$ of these spots produced quality MALDI-TOF MS spectra. These spots were annotated and displayed in Figure 1. The remaining spots failed to give any spectra (not annotated within the figure). Respective totals of 16, 15, 6, and 26 spots linked to the database of $N$. kaouthia, O. hannah, B. fasciatus, and $C$. rhodostoma were identified by PMF (Table 1). Some proteins were mapped to more than one spot, for example, those of the cobra venom factor, phospholipase $\mathrm{A}_{2}$ isozymes and L-amino-acid oxidase. Although they produced relatively good quality spectra, a few spots from the 2-DE of the four venom species were unmatchable with proteins belonging to their respective venoms by either of the two database searches.

\section{Discussion}

In this study, the 2-DE of the various snake venoms displayed prominent vertical bands that hampered the identification of bioactive proteins. Similar bands were also observed by other researchers. For instance, Marshall and Williams [14] as well as Saravia et al. [15] reported similar findings in their works on Crotalus and Bothrops asper snake venoms, respectively. 

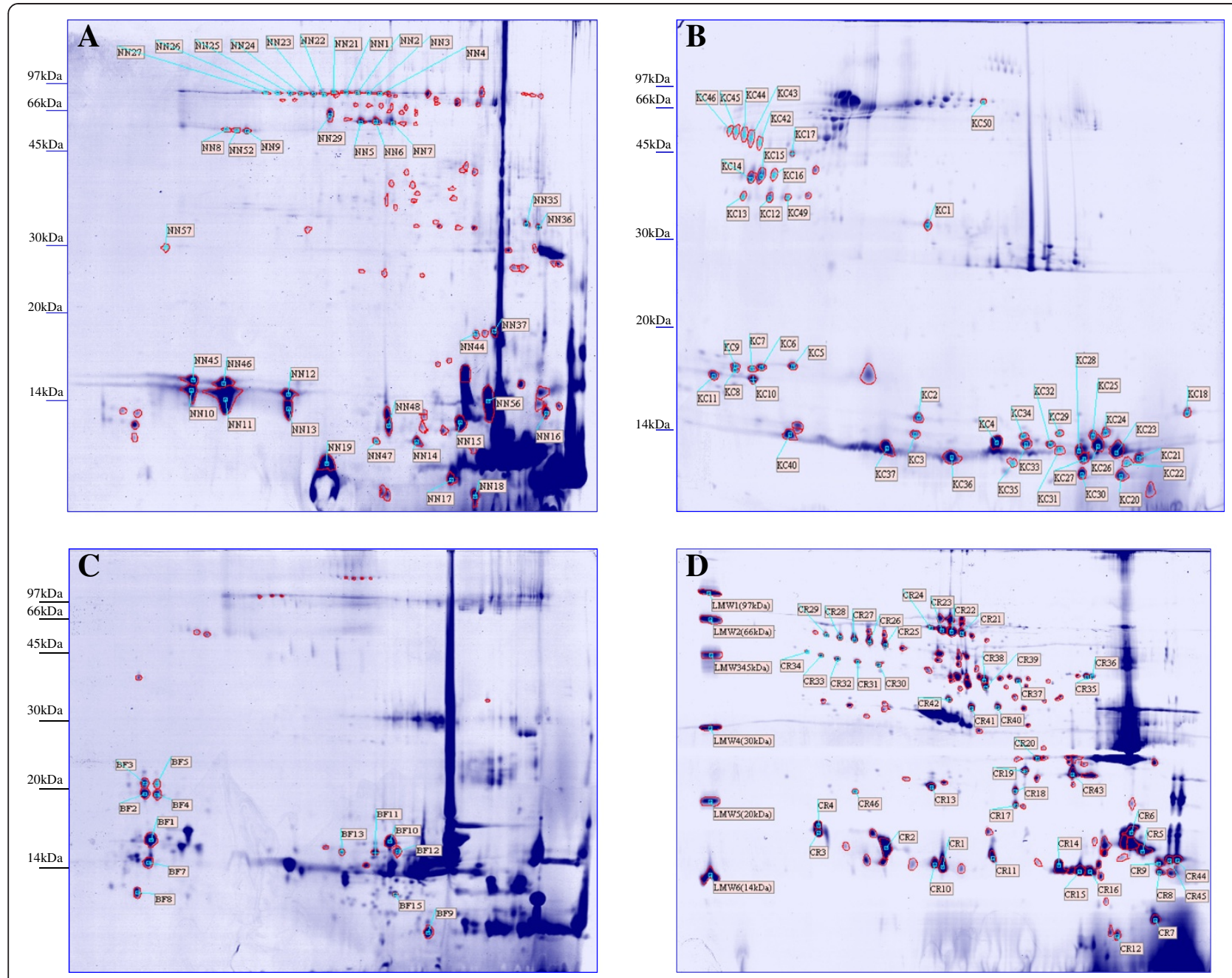

Figure 1 Proteome maps of the snake venoms of (A) N. kaouthia, (B) O. hannah, (C) B. fasciatus, and (D) C. rhodostoma with IPG 3-10 $(300 \mu \mathrm{g}$ protein, $18 \mathrm{~cm}$ ), 15\% T, Coomassie blue staining showing the annotated spots of the four venoms. The spots were detected and annotated by using the software Image Master 2D Platinum. These protein spots were identified from the 2-DE gel stained by Coomassie blue, tryptic-digested, extracted and analyzed in duplicates per spot with MALDI-TOF MS in reflectron mode.

As expected, the 2-DE images from the venoms of the four snake species demonstrated the complexity of polypeptide constituents and the known fact that the composition of snake venoms is 70 to $90 \%$ proteins [16]. The 2 -DE of the four species showed obvious variations in protein map patterns. The distinctive protein maps obtained in this study may enable species identification, which is of clinical importance. The characteristic protein map of $O$. hannah, which displayed dissimilarities in relation to the other two elapids, exemplified the significance of this purpose. The 2-DE venom proteome profile of $O$. hannah displayed numerous protein spots at the higher molecular mass region similar to the viper rather than the other two elapids. This finding is substantiated by reports from Ohsaka [17] describing the exceptional existence of hemorrhagic activity provoked by $O$. hannah venom similar to that exerted by Viperid venoms while none of the Elapidae venoms exhibits similar hemorrhagic activity. The hemorrhagic activity of the major hemorrhagin, known as hannah toxin in O. hannah, was first demonstrated by Tan and Saifuddin [18] in rabbits. Further investigation may enable potential species-specific molecular markers to be identified or detected under different gel conditions, similar to biomarkers for the purpose of species identification or disease specification (e.g. in prognosis/diagnosis of various cancers). A study by Guércio et al. [19] had also postulated the potential of differential analyses of snake venom proteomes on the development of ontogenetic molecular markers via the identification of groupspecific proteins.

To assess the venoms' proteomics profiles, the combination of 2-DE with MALDI-TOF was used. Our study, unlike that done by $\mathrm{Li}$ et al. [2], matched the 
Table 1 Protein identification of annotated spots in venom proteomes of $N$. kaouthia, O. hannah, B. fasciatus and C. rhodostoma

\begin{tabular}{|c|c|c|c|c|c|c|c|}
\hline Annotated spot & Database & Identified protein & Accession number & Hits & $\mathrm{SC}, \%$ & $\mathrm{Mw}, \mathrm{kDa}$ & $\mathrm{pl}$ \\
\hline \multicolumn{8}{|l|}{ N. kaouthia } \\
\hline NN5 & ExPASy & Hemorrhagic metalloproteinase kaouthiagin & P82942 & 6 & 13 & 44493 & 6.66 \\
\hline NN8 & ExPASy & Cobra venom factor beta chain & Q91132 & 7 & 20 & 43574 & 5.26 \\
\hline NN9 & MASCOT & Cobra venom factor precursor & AAA68989 & 10 & 6 & 184401 & 5.99 \\
\hline NN10 & ExPASy & Phospholipase $A_{2}$ isozyme 2 & P00597 & 4 & 39 & 13271 & 5.16 \\
\hline NN11 & ExPASy & Phospholipase $A_{2}$ isozyme 2 & P00597 & 7 & 67 & 13271 & 5.16 \\
\hline NN12 & ExPASy & Phospholipase $A_{2}$ isozyme 1 & P00596 & 3 & 35 & 13456 & 4.91 \\
\hline NN13 & ExPASy & Phospholipase $\mathrm{A}_{2}$ isozyme 2 & P00597 & 4 & 41 & 13271 & 5.16 \\
\hline NN14 & ExPASy & Long neurotoxin 1 (neurotoxin 3) (alpha-cobratoxin) & P01391 & 2 & 34 & 7831 & 8.59 \\
\hline NN15 & ExPASy & Muscarinic toxin-like protein 2 (MTLP-2) & P82463 & 8 & 85 & 7299 & 8.18 \\
\hline NN16 & ExPASy & Thaicobrin & P82885 & 6 & 77 & 12038 & 9.16 \\
\hline NN17 & ExPASy & Muscarinic toxin-like protein 3 (MTLP-3) & P82464 & 2 & 45 & 7624 & 8.13 \\
\hline NN19 & ExPASy & Cytotoxin 1 & P60305 & 2 & 28 & 6701 & 9.16 \\
\hline NN37 & MASCOT & Thaicobrin & P82885 & 4 & 44 & 12030 & 9.17 \\
\hline NN45 & ExPASy & Phospholipase $A_{2}$ isozyme 1 & P00596 & 4 & 39 & 13456 & 4.91 \\
\hline NN46 & ExPASy & Phospholipase $A_{2}$ isozyme 1 & P00596 & 2 & 17 & 13456 & 4.91 \\
\hline NN52 & ExPASy & Cobra venom factor beta chain & Q91132 & 4 & 11 & 43574 & 5.26 \\
\hline \multicolumn{8}{|l|}{ O. hannah } \\
\hline KC5 & ExPASy & Phospholipase $\mathrm{A}_{2}$ & Q9DF56 & 2 & 22 & 13931 & 4.83 \\
\hline KC6 & ExPASy & Phospholipase $A_{2}$ acidic 2 & Q9DF33 & 4 & 33 & 13191 & 4.41 \\
\hline KC9 & ExPASy & Phospholipase $A_{2}$ acidic 2 & Q9DF33 & 4 & 44 & 13191 & 4.41 \\
\hline KC10 & ExPASy & Phospholipase $A_{2}$, acidic 2 & Q9DF33 & 3 & 19 & 13190 & 4.42 \\
\hline KC18 & ExPASy & Ohanin & P83234 & 5 & 57 & 11952 & 9.57 \\
\hline KC20 & ExPASy & Trypsin and chymotrypsim bi-functional serine protease inhibitor & B6RLX2 & 5 & 86 & 6346 & 8.59 \\
\hline KC23 & ExPASy & Long neurotoxin 1 (neurotoxin A) & P01387 & 2 & 47 & 8106 & 8.04 \\
\hline KC24 & MASCOT & Thioredoxin protein & Q98TX1 & 3 & 38 & 11995 & 5.30 \\
\hline KC25 & ExPASy & Long neurotoxin $\mathrm{OH}-17$ & Q53B54 & 4 & 50 & 8037 & 8.34 \\
\hline KC26 & ExPASy & Long neurotoxin $\mathrm{OH}-55$ & Q53B58 & 7 & 93 & 7919 & 8.34 \\
\hline KC27 & ExPASy & Long neurotoxin 4 & P80156 & 3 & 36 & 8014 & 8.05 \\
\hline KC32 & ExPASy & Muscarinic toxin-like protein 3 homolog & A8N286 & 2 & 22 & 7542 & 7.44 \\
\hline KC33 & ExPASy & Long neurotoxin $\mathrm{OH}-55$ & Q53B58 & 2 & 42 & 7919 & 8.34 \\
\hline KC37 & ExPASy & Weak toxin DE-1 & P01412 & 2 & 32 & 7027 & 5.49 \\
\hline KC50 & ExPASy & Complement-depleting factor & ABN72543 & 9 & 6 & 184237 & 6.12 \\
\hline \multicolumn{8}{|l|}{ B. fasciatus } \\
\hline BF1 & ExPASy & Phospholipase $A_{2}$ homolog & P29601 & 3 & 39 & 13104 & 4.37 \\
\hline BF2 & ExPASy & Phospholipase $A_{2}$ KBf-grlB & P0C551 & 3 & 26 & 14157 & 4.78 \\
\hline BF4 & ExPASy & Phospholipase $A_{2}$ KBf-grlB & P0C551 & 3 & 26 & 14157 & 4.78 \\
\hline BF7 & ExPASy & Phospholipase $A_{2}$ homolog & P29601 & 2 & 19 & 13104 & 4.37 \\
\hline BF9 & ExPASy & Phospholipase $A_{2} 13$ & P00627 & 3 & 71 & 3704 & 8.91 \\
\hline BF15 & ExPASy & Phospholipase $A_{2}$ isozyme 6 & P00627 & 2 & 25 & 13066 & 7.94 \\
\hline \multicolumn{8}{|l|}{ C. rhodostoma } \\
\hline CR1 & ExPASy & Phospholipase $\mathrm{A}_{2} \mathrm{H1E6}$ & Q9PVF2 & 8 & 48 & 13919 & 5.51 \\
\hline CR2 & ExPASy & Rhodocetin alpha subunit & P81397 & 8 & 67 & 15962 & 5.16 \\
\hline
\end{tabular}


Table 1 Protein identification of annotated spots in venom proteomes of $\boldsymbol{N}$. kaouthia, $\boldsymbol{O}$. hannah, B. fasciatus and C. rhodostoma (Continued)

\begin{tabular}{|c|c|c|c|c|c|c|c|}
\hline CR5 & ExPASy & Phospholipase $A_{2}$ W6D49 & Q9PVF4 & 10 & 40 & 13689 & 8.34 \\
\hline CR6 & ExPASy & Phospholipase $A_{2}$ W6D49 & Q9PVF4 & 11 & 40 & 13689 & 8.34 \\
\hline CR14 & ExPASy & Disintegrin rhodostomin & P30403 & 8 & 93 & 7330 & 6.70 \\
\hline CR15 & ExPASy & Rhodocytin subunit beta & Q91840 & 6 & 69 & 14369 & 7.08 \\
\hline CR16 & ExPASy & Rhodocytin subunit beta & Q91840 & 6 & 69 & 14369 & 7.08 \\
\hline CR17 & ExPASy & Metalloproteinase kistomin & P0CB14 & 2 & 9 & 25846 & 6.41 \\
\hline CR18 & ExPASy & Metalloproteinase kistomin & POCB14 & 2 & 9 & 25846 & 6.41 \\
\hline CR19 & ExPASy & Halystase & P81176 & 2 & 14 & 26483 & 6.70 \\
\hline CR21 & MASCOT & L-amino acid oxidase & AJ271725 & 7 & 22 & 58184 & 6.05 \\
\hline CR22 & MASCOT & L-amino acid oxidase & AJ271725 & 15 & 31 & 58184 & 6.05 \\
\hline CR23 & ExPASy & L-amino acid oxidase & P81382 & 12 & 26 & 56228 & 6.04 \\
\hline CR25 & ExPASy & Ancrod (EC 3.4.21.74) (venombin A) (protein C activator) & P26324 & 7 & 27 & 26571 & 8.59 \\
\hline CR27 & ExPASy & Ancrod (EC 3.4.21.74) (venombin A) (protein C activator) & P26324 & 9 & 27 & 26571 & 8.59 \\
\hline \multirow[t]{2}{*}{ CR28 } & MASCOT & Venombin A (EC 3.4.21.74) & S20407 & 5 & 16 & 26553 & 8.61 \\
\hline & & 1 [validated] & & & & & \\
\hline \multirow[t]{2}{*}{ CR29 } & MASCOT & Venombin A (EC 3.4.21.74) & S20407 & 4 & 16 & 26553 & 8.61 \\
\hline & & 1 [validated] & & & & & \\
\hline CR30 & MASCOT & Ancrod-like protein & CAA01524 & 3 & 10 & 25213 & 8.44 \\
\hline CR31 & MASCOT & Ancrod-like protein & CAA01524 & 4 & 14 & 25213 & 8.44 \\
\hline CR32 & MASCOT & Ancrod-like protein & CAA01524 & 4 & 14 & 25213 & 8.44 \\
\hline CR33 & MASCOT & Ancrod-like protein & CAA01524 & 3 & 10 & 25213 & 8.44 \\
\hline CR34 & MASCOT & Ancrod-like protein & CAA01524 & 14 & 4 & 25213 & 8.44 \\
\hline CR39 & MASCOT & L-amino acid oxidase & AJ271725 & 8 & 21 & 58184 & 6.05 \\
\hline CR40 & MASCOT & Ancrod-like protein & CAA01524 & 4 & 13 & 29314 & 8.54 \\
\hline CR41 & ExPASy & Ancrod [precursor] & P47797 & 4 & 13 & 26461 & 8.53 \\
\hline CR43 & ExPASy & Metalloproteinase kistomin & POCB14 & 2 & 9 & 25846 & 6.41 \\
\hline
\end{tabular}

venom peptide masses of the particular snake species to their corresponding protein databases, found in the Taxonomy Browser. The Taxonomy Browser contained in the Entrez database (http://www.ncbi.nlm.nih.gov) provided the total number of proteins available for matching for each of the four snake venoms. The respective numbers of known proteins available as of October 2013 were 157 for N. kaouthia, 192 for O. hannah, 130 for B. fasciatus and 84 for $C$. rhodostoma. The protein database was constructed based on the sequence data from the translated coding regions from DNA sequences in GenBank, EMBL, and DDBJ as well as protein sequences submitted to Protein Information Resource (PIR), SWISS-PROT, Protein Research Foundation (PRF), and Protein Data Bank (PDB) (sequences from solved structures). It was obvious that the database was incomplete for snake venom matching, compared with 784,406 proteins available for Homo sapiens (human), and 123,173 for Bos taurus (cattle) proteins. Nevertheless, the snake venom protein database is still of greater value than those of some other venomous species such as Chironex yamaguchii (sea wasp) with only two proteins, Hadrurus aztecus (scorpion) with one, and Dolomedes plantarius (spider) with none, to name a few, for matching.

A closer examination of the snake-venom-protein database disclosed the following information: some of the proteins were not found in the venom but were evidently found elsewhere in the snake's body, for example, the nerve growth factor (located in the nervous system), $\mathrm{NADH}$ dehydrogenase and cytochrome $\mathrm{b}$ (located in mitochondria) and oocyte maturation factor (located in the reproductive system). Also, most of the venom proteins were precursor forms or polypeptide chains of the same protein, for example: phospholipase $\mathrm{PLA}_{2}$ precursor and chain A, crystal structure of L-amino acid oxidase. Based on these factors, therefore, the snake venom proteins available for matching in the database were, in fact, much more limited. 
Nevertheless, even with these limitations, many important proteins were identified in the 2-DE of the 4 species. A total of 63 proteins were identified: C. rhodostoma - 26, N. kaouthia - 16, O. hannah - 15 and B. fasciatus- 6 . Venoms from snakes contain various types of toxins such as cardiotoxins and neurotoxins, biological factors that are anti-coagulant, anti-thrombotic, antiplatelet binding, as well as active enzymes including phospholipase, endo- and exonucleotidases, hyaluronidase, neuraminidase, protease and many others. Generally, the non-enzymatic protein or polypeptide toxins dominate the lethal actions of elapids (e.g. cobra and krait) and sea snakes, whereas enzymes appear to play a more important role in the lethality of viperid (viper) and crotalid (pit viper) venoms [16].

In the present study, the phospholipase $\mathrm{A}_{2}\left(\mathrm{PLA}_{2}\right)$ group of enzymes was identified in all four species. At least one of these enzyme types was identified in each of the four species studied (Table 1). This finding is not surprising given that extensive studies on venom have demonstrated an accelerated natural selection force that drives the evolution of a multitude of extremely potent snake toxins from an ancestral PLA $_{2}$ with digestive function $[20,21]$. Hundreds of species of venomous snakes of the families Elapidae and Viperidae were shown to have evolved a wide variety of venoms that contain varying proportions of toxins endowed with PLA $\mathrm{P}_{2}$ activity, characterized by their neurotoxicity, myotoxicity, as well as anticoagulant and edema-inducing properties [21-23]. Hence, in snake venom, $\mathrm{PLA}_{2}$ enzymes, in addition to their possible role in digesting the prey, exhibit a wide variety of pharmacological effects through interfering with normal physiological processes [24]. It is well known that some of the most toxic and potent pharmacologically active components of snake venoms are either $\mathrm{PLA}_{2}$ enzymes or their protein complexes. For example, all known presynaptic neurotoxins from snake venom are $\mathrm{PLA}_{2}$ enzymes or contain at least one $\mathrm{PLA}_{2}$ as an integral part $[25,26]$. PLA $A_{2}$ myotoxins are more potent and act faster than their non-enzymatic counterparts [27].

PMF using MS also allowed the identification of long neurotoxins in both the cobra species studied. Unlike presynaptic beta-neurotoxins that exhibit varying PLA $\mathrm{P}_{2}$ activities, these long neurotoxins are classified as alpha-neurotoxins that affect the post-synaptic membrane [28]. Post-synaptic neurotoxins have been identified only in venoms from the families Elapidae and Hydrophiidae (sea snakes). They are nicotinic receptor antagonists on the skeletal muscle and display different binding kinetics and affinity for subtypes of nicotinic receptors [29]. Other significant neurotoxins, such as the muscarinic toxin-like proteins (MTLP), including ohanin and thaicobrin, were also identified in the cobra venoms.
Rhodocetin, another important protein identified in $C$. rhodostoma venom, is a $\mathrm{Ca}^{2+}$-dependent lectin-related protein (CLP) that is a potent platelet aggregation inhibitor induced by collagen. It is a prime example of a CLP dimer, in which the two subunits are held together by non-covalent interactions and act synergistically to elicit the biological activity, affecting platelet aggregation and blood coagulation, important in cellular thrombosis and non-cellular processes in homeostasis [30,31]. This protein was also demonstrated to antagonize stromal tumor invasion in vitro and other $\alpha 2 \beta 1$ integrin-mediated cell functions [32]. The proteomic approach applied in the present study also successfully identified a significant number of peptidases, namely zinc metalloproteinase or disintegrin, ancrod or venombin A, and L-amino-acid oxidases which display the well-documented hemotoxic properties of the viper's venom. Disintegrin exhibits hemorrhagic activities by binding to the glycoprotein IIb-IIIa receptor on the platelet surface, thus inhibiting fibrinogen interaction with platelet receptors while Lamino-acid oxidases exert hemorrhagic effects by catalyzing oxidative deamination of hydrophobic and aromatic L-amino acids [33-36]. L-amino-acid oxidases have also recently been shown to display antibacterial properties [37]. On the other hand, ancrod is a thrombin-like serine protease that selectively cleaves the fibrinopeptides, resulting in aberrant fibrinogen that is unable to form dispersible blood clots [38].

Despite the identification of major proteins in the four snake species, a large number of spots from the 2-DE were unidentifiable with their respective snake venom protei ns even though the spots displayed high-quality MALDI-TOF-MS spectra. This was similar to the finding of another research group who identified proteins in two types of snake venoms: Naja naja atra and Agkistrodon halys [2]. In their study, only $50 \%$ of the spots were confirmed to have venom properties from approximately $80 \%$ of 2-DE gel spots displaying high-quality MALDITOF-MS spectra. As mentioned earlier, this was due to the unavailability of a full protein database or the result of post-translational modification (PTM). PTM of venomous proteins is a common phenomenon in snake venoms. Of a number of mechanisms inducing chemical modification of protein, glycosylation is one of the most frequently found Li et al. [2]. For instance, different degrees of glycosylation were discovered in the snake venom toxins of Crotalus atrox and Bothrops jararaca, using the fluorescent glycoprotein specific stain, Pro-QEmerald [39]. Given that the database for snake venoms is still developing, it is worth noting that easier identification remains possible in the future. This is evident when one compares the number of known proteins dating back to October 2005 (67 for N. kaouthia, 78 for $O$. hannah, 34 for B. fasciatus and 60 for C. rhodostoma) to 
the most recent Entrez protein database. Among these the protein database of $B$. fasciatus shows the most promising development, an augmentation of approximately $380 \%$, while those of $O$. hannah increased by $125 \%, N$. kaouthia by $235 \%$, and C. rhodostoma by $140 \%$.

With the comprehensive cataloguing of venom toxins, the characterization of species-specific venom proteome is therefore greatly facilitated when studying the pathophysiological effects arising from species-specific snakebites. For instance, the sequential, comparative 2-DE analysis of in vivo and in vitro effects of venom on specific plasma proteins from a patient bitten by a rattlesnake has demonstrated the pathological relationship between the snake toxins and the injury-related physiological alterations [40]. The application of proteomic tools by Escalante et al. [41] on wound exudates also revealed the tissue-damaging mechanisms of different snake venom toxins.

\section{Conclusions}

The 2-DE map of these venoms will play a vital role in the purification of their proteins by utilizing the 2-DE-guid purification applications as described by Tang et al. [42].

\section{Additional file}

Additional file 1: The peptide masses used for identifying the proteins.

\section{Competing interests}

The authors declare that they have no competing interests.

\section{Authors' contributions}

All authors contributed equally to the present work. All authors read and approved the final manuscript.

\section{Acknowledgments}

The authors would like to thank University of Malaya for providing the proteomic instrumentation to complete this study.

\section{Author details}

${ }^{1}$ Faculty of Industrial Sciences and Technology, University Malaysia Pahang, Lebuhraya Tun Razak, Kuantan, Pahang Darul Makmur 26300, Malaysia. ${ }^{2}$ Institute of Biological Sciences, University of Malaya, Kuala Lumpur 50603 , Malaysia.

Received: 23 October 2013 Accepted: 17 February 2014 Published: 4 March 2014

\section{References}

1. Lim BL: Poisonous snakes of Peninsular Malaysia. $3^{\text {rd }}$ Revised edition. Malaysian Nature Society: Kuala Lumpur; 1991.

2. Li S, Wang J, Zhang X, Ren Y, Wang N, Zhao K, Chen X, Zhao C, Li X, Shao J, Yin J, West MB, Xu N, Liu S: Proteomic characterization of two snake venoms: Naja naja atra and Agkistrodon halys. Biochem J 2004, 384(Pt 1):119-127

3. Fox JW, Serrano SM: Exploring snake venom proteomes: multifaceted analyses for complex toxin mixtures. Proteomics 2008, 8(4):909-920.

4. Lee CY: Chemistry and pharmacology of polypeptide toxins in snake venoms. Annu Rev Pharmacol 1972, 12:265-281.

5. Fox JW, Kamiguti AS, Theakston RDG, Shannon JD, Stefansson B, Serrano SMT, Camargo ACM, Sherman N: Role of discovery science in toxinology: examples in venom proteomics. In Perspectives in molecular toxinology. Edited by Menez A. Chichester: John Wiley \& Sons; 2002:97-106.

6. Creer S, Malhotra A, Thorpe RS, Stöcklin R, Favreau PS, Hao Chou WS: Genetic and ecological correlates of intraspecific variation in pitviper venom composition detected using matrix-assisted laser desorption time-of-flight mass spectrometry (MALDI-TOF-MS) and isoelectric focusing. J Mol Evol 2003, 56(3):317-329.

7. Nawarak J, Phutrakul S, Chen ST: Analysis of lectin-bound glycoproteins in snake venom from the Elapidae and Viperidae families. J Proteome Res 2004, 3(3):383-392.

8. Juarez P, Sanz L, Calvete JJ: Snake venomics: characterization of protein families in Sistrurus barbouri venom by cysteine mapping, N-terminal sequencing, and tandem mass spectrometry analysis. Proteomics 2004, 4(2):327-338.

9. Toyama OD, Boschero CA, Martins AM, Fonteles CM, Monteiro SH, Toyama $\mathrm{MH}$ : Structure-function relationship of new crotamine isoform from the Crotalus durissus cascavella. Protein J 2005, 24(1):9-19.

10. Oliveira DG, Toyama MH, Novello JC, Beriam LO, Marangoni S: Structural and functional characterization of basic PLA2 isolated from Crotalus durissus terrificus venom. J Protein Chem 2002, 21(3):161-168.

11. Vejayan J, Shin Yee L, Ponnudurai G, Ambu S, Ibrahim H: Protein profile analysis of Malaysian snake venoms by two-dimensional gel electrophoresis. J Venom Anim Toxins Ind Trop Dis 2010, 16(4):623-630.

12. Bradford MM: A rapid and sensitive method for the quantitation of microgram quantities of protein utilizing the principle of protein-dye binding. Anal Biochem 1976, 72:248-254.

13. Nawarak J, Sinchaikul S, Wu CY, Liau MY, Phutrakul S, Chen ST: Proteomics of snake venoms from Elapidae and Viperidae families by multidimensional chromatographic methods. Electrophoresis 2003, 24(16):2838-2854.

14. Marshall T, Williams KM: Analysis of snake venoms by sodium dodecyl sulfate-polyacrylamide gel electrophoresis and two-dimensional electrophoresis. Appl Theor Electrophor 1994, 4(1):25-31.

15. Saravia P, Rojas E, Escalante T, Arce V, Chaves E, Velásquez R, Lomonte B, Rojas G, Gutiérrez JM: The venom of Bothrops asper from Guatemala: toxic activities and neutralization by antivenoms. Toxicon 2001, 39(2-3):401-405.

16. Tu AT: Venoms: chemistry and molecular biology. New York: John Wiley \& Sons; 1977.

17. Ohsaka A: Hemorrhagic, necrotizing and edema-forming effects of snake venoms. In Handbook of Experimental Pharmacology, Volume 52. Edited by Lee CY. Berlin: Springer; 1979:481-546.

18. Tan NH, Saifuddin MN: Isolation and characterization of a hemorrhagin from the venom of Ophiophagus hannah (king cobra). Toxicon 1990 28(4):385-392.

19. Guércio RAP, Shevchenko A, Shevchenko A, López-Lozano JL, Paba J, Sousa MV, Ricart CAO: Ontogenetic variations in the venom proteome of the Amazonian snake Bothrops atrox. Proteome Sci 2006, 4:1-14.

20. Ogawa T, Nakashima K-I, Nobuhisa I, Deshimaru M, Shimohigashi Y, Fukumaki Y, Sakaki Y, Hattori S, Ohno M: Accelerated evolution of snake venom phospholipase $\mathrm{A} 2$ isozymes for acquisition of diverse physiological functions. Toxicon 1996, 34(11-12):1229-1236.

21. Montecucco C, Gutierrez JM, Lomonte B: Cellular pathology induced by snake venom phospholipase A2 myotoxins and neurotoxins: common aspects of their mechanisms of action. Cell Mol Life Sci 2008, 65(18):2897-2912.

22. Boffa GA, Boffa MC, Winchenne JJ: A phospholipase A2 with anticoagulant activity. I. Isolation from Vipera berus venom and properties. Biochim Biophys Acta 1976, 429(3):839-852.

23. Vishwanath BS, Kini RM, Gowda TV: Characterization of three edemainducing phospholipase $A_{2}$ enzymes from habu (Trimeresurus flavoviridis) venom and their interaction with the alkaloid aristolochic acid. Toxicon 1987, 25(5):501-515.

24. Kini RM: Excitement ahead: structure, function and mechanism of snake venom phospholipase A2 enzymes. Toxicon 2003, 42(8):827-840.

25. Bon C: Multicomponent neurotoxic phospholipases A2. In Venom phospholipase A2 enzymes: structure, function and mechanism. Edited by Kini RM. Chichester: John Wiley \& Sons; 1997:269-285.

26. Fletcher JE, Rosenberg $P$ : The cellular effects and mechanisms of action of presynaptically acting phospholipase A2 enzymes. In Venom phospholipase A2 enzymes: structure, function and mechanism. Edited by Kini RM. Chichester: John Wiley \& Sons; 1997:413-454. 
27. Gubensek F, Kriaj I, Pungerar J: Monomeric phospholipase A2 neurotoxins. In Venom phospholipase A2 enzymes: structure, function and mechanism. Edited by Kini RM. Chichester: John Wiley \& Sons; 1997:245-268

28. Lewis RL, Gutmann L: Snake venoms and the neuromuscular junction. Semin Neurol 2004, 24(2):175-179.

29. Hodgson WC, Wickramaratna JC: In vitro neuromuscular activity of snake venoms. Clin Exp Pharmacol Physiol 2002, 29(9):807-814.

30. Kornalik F: The influence of snake venom proteins on blood coagulation. In Snake Toxin. Edited by Harvey AL. New York: Pergamon Press; 1991:323-383.

31. Wang R, Kini RM, Chung MC: Rhodocetin, a novel platelet aggregation inhibitor from the venom of Calloselasma rhodostoma (Malayan pit viper): synergistic and noncovalent interaction between its subunits. Biochemistry 1999, 38(23):7584-7593.

32. Eble JA, Niland S, Dennes A, Schmidt-Hederich A, Bruckner P, Brunner G: Rhodocetin antagonizes stromal tumor invasion in vitro and other alpha2beta1 integrin-mediated cell functions. Matrix Biol 2002. 21(7):547-558.

33. Dennis MS, Henzel WJ, Pitti RM, Lipari MT, Napier MA, Deisher TA, Bunting S, Lazarus RA: Platelet glycoprotein Illb-llla protein antagonists from snake venoms: evidence for a family of platelet aggregation inhibitors. Proc Natl Acad Sci U S A 1990, 87(7):2471-2475.

34. Gould RJ, Polokoff MA, Friedman PA, Huang TF, Holt JC, Cook JJ, Niewiarowski S: Disintegrins: a family of integrin inhibitory proteins from viper venoms. Proc Soc Exp Biol Med 1990, 195(2):168-171.

35. Au LC, Lin SB, Chou JS, Teh GW, Chang KJ, Shih CM: Molecular cloning and sequence analysis of the CDNA for ancrod, a thrombin-like enzyme from the venom of Calloselasma rhodostoma. Biochem J 1993, 294(Pt 2):387-390.

36. MacHeroux P, Seth O, Bollschweiler C, Schwarz M, Kurfurst M, Au LC, Ghisla S: L-amino-acid oxidase from the Malayan pit viper Calloselasma rhodostoma. Comparative sequence analysis and characterization of active and inactive forms of the enzyme. Eur I Biochem 2001, 268(6):1679-1686.

37. Tonismagi K, Samel M, Trummal K, Ronnholm G, Siigur J, Kalkkinen N, Siigur E: L-amino acid oxidase from Vipera lebetina venom: isolation, characterization, effects on platelets and bacteria. Toxicon 2006, 48(2):227-237

38. Au LC, Chou JS, Chang KJ, The GW, Lin SB: Nucleotide sequence of a full-length CDNA encoding a common precursor of platelet aggregation inhibitor and hemorrhagic protein from Calloselasma rhodostoma venom. Biochim Biophys Acta 1993, 1173(2):243-245.

39. Serrano SMT, Shannon JD, Wang D, Camargo ACM, Fox JW: A multifaceted analysis of viperid snake venoms by two-dimensional gel electrophoresis: an approach to understanding venom proteomics. Proteomics 2005, 5(2):501-510.

40. Bagley EA, Lonberg-Holm K, Pandya BV, Budzynski AZ: Two-dimensional gel electrophoretic analysis of plasma proteins from a patient bitten by a rattlesnake. Electrophoresis 1983, 4(3):238-241.

41. Escalante T, Rucavado A, Pinto AFM, Terra RMS, Gutierrez JM, Fox JW: Wound exudate as a proteomic window to reveal different mechanisms of tissue damage by snake venom toxins. J Proteome Res 2009, 8(11):5120-5131.

42. Tang MS, Vejayan J, Ibrahim $\mathrm{H}$ : The concept of two-dimensional electrophoresis-guided purification proven by isolation of rhodocetin from Calloselasma rhodostoma (Malayan pit viper). J Venom Anim Toxins Ind Trop Dis 2011, 17(4):442-450.

doi:10.1186/1678-9199-20-6

Cite this article as: Vejayan et al:: Comparative analysis of the venom proteome of four important Malaysian snake species. Journal of Venomous Animals and Toxins including Tropical Diseases 2014 20:6.

\section{Submit your next manuscript to BioMed Central and take full advantage of:}

- Convenient online submission

- Thorough peer review

- No space constraints or color figure charges

- Immediate publication on acceptance

- Inclusion in PubMed, CAS, Scopus and Google Scholar

- Research which is freely available for redistribution

Submit your manuscript at www.biomedcentral.com/submit
Ciomed Central 